\title{
Factors influencing pacing in triathlon
}

This article was published in the following Dove Press journal:

Open Access Journal of Sports Medicine

16 September 2014

Number of times this article has been viewed

\author{
Sam SX Wu' \\ Jeremiah J Peiffer ${ }^{2}$ \\ Jeanick Brisswalter ${ }^{3}$ \\ Kazunori Nosaka' \\ Chris R Abbiss' \\ 'Centre for Exercise and Sports \\ Science Research, School of Exercise \\ and Health Sciences, Edith Cowan \\ University, Perth, WA, Australia; \\ ${ }^{2}$ School of Psychology and Exercise \\ Science, Murdoch University, Perth, \\ WA, Australia; ${ }^{3}$ Laboratory of Human \\ Motricity, Education Sport and Health, \\ University of Nice Sophia Antipolis, \\ Nice, France
}

Correspondence: Sam Shi Xuan Wu School of Exercise and Health Sciences, Edith Cowan University, 270 Joondalup

Drive, Joondalup, WA 6027, Australia

Tel +6I 863045740

Fax +6I 863045036

Email s.goh@ecu.edu.au
Abstract: Triathlon is a multisport event consisting of sequential swim, cycle, and run disciplines performed over a variety of distances. This complex and unique sport requires athletes to appropriately distribute their speed or energy expenditure (ie, pacing) within each discipline as well as over the entire event. As with most physical activity, the regulation of pacing in triathlon may be influenced by a multitude of intrinsic and extrinsic factors. The majority of current research focuses mainly on the Olympic distance, whilst much less literature is available on other triathlon distances such as the sprint, half-Ironman, and Ironman distances. Furthermore, little is understood regarding the specific physiological, environmental, and interdisciplinary effects on pacing. Therefore, this article discusses the pacing strategies observed in triathlon across different distances, and elucidates the possible factors influencing pacing within the three specific disciplines of a triathlon.

Keywords: cycle, endurance, multisport, pacing strategy, run, swim

\section{Introduction}

Triathlon is a unique sport that consists of consecutive swim, cycle, and run disciplines completed over a variety of distances. The origin of triathlon is unclear; however, the first officially organized Ironman triathlon was conducted in Hawaii in 1978 with only 12 participants. ${ }^{1}$ Over the last 30 years, the popularity of this sport has increased tremendously, driving the emergence of other shorter (ie, sprint, Olympic, half-Ironman) and longer (ie, double to $20 \times$ Ironman) distances as well as other formats (ie, off-road) of triathlons. ${ }^{2}$ Of these, the most popular standard triathlon distances include the sprint (swim: $0.75 \mathrm{~km}$, cycle: $20 \mathrm{~km}$, run: $5 \mathrm{~km}, \sim 1$ hour), Olympic (swim: $1.5 \mathrm{~km}$, cycle: $40 \mathrm{~km}$, run: $10 \mathrm{~km}, \sim 2$ hours), half-Ironman (swim: $1.9 \mathrm{~km}$, cycle: $90 \mathrm{~km}$, run: $21.1 \mathrm{~km}, \sim 4-5$ hours), and Ironman (swim: $3.8 \mathrm{~km}$, cycle: $180 \mathrm{~km}$, run: $42.2 \mathrm{~km}, 8-17$ hours). Due to the large variations in distances, and thus exercise duration, the metabolic demands and physiological responses during such races could vary greatly. 3,4

It is well accepted that the distribution of speed, work, or energy expenditure throughout an exercise task is extremely important in optimizing performance. ${ }^{5-7}$ This pattern of energy expenditure or distribution of speed is known as "pacing" and, although often used interchangeably, differs slightly to the term "pacing strategy", which refers to a conscious strategy or plan to manipulate effort. Indeed, it has been proposed that the distribution of speed throughout an exercise task may be partially regulated on a subconscious $l e v e l^{8}$ and is, therefore, presumably disjointed somewhat from the athletes' pre-race strategy or plan. Within this context, energy expenditure 
is constantly regulated in response to complex interactions between peripheral feedback and central drive to ensure physiological systems are maintained within homeostatic or manageable limits, whilst delaying the negative effects of fatigue and, thus, maximizing performance. ${ }^{1,5,9-13}$ More recently, Edwards and Polman ${ }^{14}$ introduced the concept of a "pacing awareness" model, which provides an alternative theory by proposing that pacing regulation occurs via relative states of awareness, ranging from minimum (sleep) to maximum (fully aware), rather than exclusive subconscious or conscious states. For instance, minor corrections in homeostasis require little or no conscious awareness to accomplish; however, strenuous activities involving large metabolic disturbances such as glycogen depletion necessitate a more conscious approach requiring significant behavioral alterations. ${ }^{14}$ It is plausible that metabolic demands will differ among the several disciplines and various competition distances within triathlon and, thus, the levels of subconscious and conscious awareness.

To date, studies examining the mechanisms that influence pacing have focused on single sport events such as running, ${ }^{15,16}$ cycling, ${ }^{6,7,17-19}$ swimming, ${ }^{20,21}$ and rowing. ${ }^{22}$ These single sport studies have identified possible factors regulating pace, including the availability of fuel substrates, ${ }^{4,23,24}$ thermoregulation, ${ }^{9,24}$ previous experience, ${ }^{17,25,26}$ knowledge of exercise duration, ${ }^{25,27}$ physical fitness, ${ }^{23}$ cognitive capacity, ${ }^{28}$ mood, ${ }^{29,30}$ peripheral feedback,,${ }^{25}$ and central regulation. ${ }^{4,5}$ However, the majority of these studies has been performed under laboratory conditions and may not precisely replicate the demands during actual triathlon competition. Understanding pacing during such events is complex since athletes are required to not only distribute their effort over the entire event but also over each independent discipline. Indeed, recent studies have demonstrated that the self-selected pacing patterns differ greatly during the swim, ${ }^{31-34}$ cycle, ${ }^{10,32-35}$ and run $^{11,12,32-34}$ portions of triathlon events.

The sport of triathlon provides a unique model for pacing analysis, due to the involvement of sequential swim, cycle, and run disciplines in continuum, and the ability to examine the influence of race distance on pacing. To date, a comprehensive review examining factors that may be responsible for differences in pacing over various triathlon distances and disciplines is currently lacking. As such, the strategy or strategies that assist in optimizing performance during the various standard triathlon events is presently unclear. Therefore, the purpose of this review is to: 1) identify factors regulating and influencing pacing in triathlon; 2) discuss the effectiveness of and provide recommendations for the currently adopted pacing strategies in triathlon; and 3) examine the influence and relationships of performance during individual disciplines on/with subsequent and overall triathlon performance.

\section{Factors influencing pacing in triathlon}

Of the multitude of factors influencing pacing, some important factors associated with triathlon performance include: exercise distance/duration; ${ }^{13}$ race dynamics (drafting conditions, ${ }^{36}$ influence of other competitors $;{ }^{37,38}$ ) environmental factors (sea currents, wind velocities, ${ }^{39,40}$ topography ${ }^{3,41,42}$ ); transitions (swim to cycle, cycle to run); age; ${ }^{32,43}$ and sex. ${ }^{43-45}$ Of these factors, exercise duration appears to have the most significant influence on both the self-selected and the optimal pacing strategies selected by athletes during competition. Certainly, ultra-endurance events ( $>6$ hours) ${ }^{46}$ induce greater neuromuscular fatigue due to greater demands on metabolic substrates and psychological factors. ${ }^{5}$ Despite the important role that exercise duration plays on pacing, there is currently no research that has extensively examined the influence of race distance on pacing in triathlon. Indeed, the majority of studies that have examined the distribution of pace within the triathlon have focused on the Olympic distance triathlon, ${ }^{10,11,32-34}$ and only one study has investigated the cycle discipline of the Ironman. ${ }^{35}$ Clearly, the abovementioned factors may influence the regulation of pace during triathlon to different extents. These factors are reviewed below in the context of understanding the effectiveness of such strategies and providing recommendations for optimal pacing.

\section{Distance}

Exercise duration appears to be one of the most important factors influencing both optimal and self-selected pacing. ${ }^{22,31,61,63-66}$ Indeed, it is plausible that differences in race distance will have a significant influence on the mechanisms responsible for fatigue and, thus, athletes' pacing. ${ }^{9}$ While a gradual reduction in speed (ie, positive pacing) was observed in the Olympic ${ }^{32,33,35}$ and Ironman distance triathlons, ${ }^{35}$ the mechanisms responsible for such changes in pace are likely to vary. For instance, during shorter duration triathlon events (ie, the sprint distance), the progressive reduction in pace may be associated with metabolite accumulation and accompanying neuromuscular fatigue. Indeed, the progressive reduction in speed during relatively short duration $100 \mathrm{~m}, 200 \mathrm{~m}, 400 \mathrm{~m}$, and $800 \mathrm{~m}^{15}$ running events has been attributed to the accumulation of anaerobic metabolites, which in turn increases muscular acidity, impairing glycolysis ${ }^{48}$ and muscular 
contractions. ${ }^{49}$ However, during longer duration triathlons (ie, half-Ironman or Ironman), fatigue is likely to be associated with reductions in muscle glycogen content ${ }^{50-55}$ and neuromuscular activity. ${ }^{9,56-58}$ For instance, reduced time to fatigue during cycling and increased performance time during time trials were observed during cycling exercise without carbohydrate ingestion, as compared to carbohydrate supplementation. ${ }^{54}$ Furthermore, a reduction in carbohydrate availability has also been shown to reduce cycling pace after $\sim 2$ hours of prolonged exercise. ${ }^{55}$ Supporting the reduction in neuromuscular activity during endurance exercise, St Clair Gibson et al ${ }^{58}$ observed a progressive decline in electromyogram (EMG) activity and mean power output of intermittent $4 \mathrm{~km}$ high-intensity intervals during a $100 \mathrm{~km}$ cycling time trial.

Despite the different energy demands and physiological responses between triathlons of various distances, athletes of various caliber typically adopt a fast-start strategy, regardless of race distance. ${ }^{33,35}$ This fast start is likely to be caused by the high initial swim intensity required to achieve a good drafting position during the early portions of the swim discipline ${ }^{33,34}$ (see "Race dynamics and drafting in mass-start events"). Furthermore, evidence suggests that a fast-start pacing strategy may enhance oxygen kinetics and improve performance during short- to middle-distance (3- to 7-minute) exercise tasks. ${ }^{18,22,59}$ For instance, Bailey et al ${ }^{59}$ compared the effect of a fast-start, even-start, and slow-start pacing strategy on 3-minute cycling performance. The authors found superior performance with the fast-start ( $7 \%$ greater power output), as compared with the slow- and even-start, and attributed this to a faster oxygen consumption $\left(\mathrm{VO}_{2}\right)$ response. As such, it is possible that the adoption of a fast-start pacing strategy, especially during the swim discipline of shorter sprint triathlons, may enhance oxygen kinetics ${ }^{60}$ and improve overall swim performance. ${ }^{61}$ While the adoption of a fast-start pacing strategy minimizes the time required to reach peak velocity and may improve performance during short explosive ( $\leq 2$-minute) sporting events, ${ }^{5,40}$ the acceleration phase could have limited influence on performance during longer endurance events. Instead, due to the prolonged nature of exercise in a triathlon ( $\sim 1$ hour or more), the adoption of a fast-start pacing strategy could lead to suboptimal distribution of energy resources and cause premature fatigue. ${ }^{62,63}$ Under such circumstances, a more conservative pacing strategy that allows for the conservation of glycogenic resources may be more optimal for overall performance.

While a fast-start pacing strategy is often observed during the beginning of triathlon (ie, swim discipline), there is evidence to indicate that an even pacing strategy, achieved by maintaining a constant velocity despite varying external conditions (ie, wind and altitude), may be ideal during endurance events such as the triathlon. ${ }^{5-7,19,64}$ Within this context, endurance performance is compromised if an athlete's speed decreases below the mean speed at any time throughout the event, even if they attempt to increase power output to make up for lost time during the final stages of the race..$^{65}$ This is because an increase in velocity requires a dramatic increase in energy expenditure to overcome the nonlinear increase in resistive forces experienced, and could lead to premature fatigue. ${ }^{66,67}$ Consequently, an even pacing strategy results in the best possible balance of both propulsive and resistive forces, and thereby maximizes overall performance during endurance events of varying distance. For instance, Le Meur et $\mathrm{al}^{11}$ observed a more even running pace in the best runners during the $10 \mathrm{~km}$ run of an Olympic-distance triathlon, despite changes in gradient, and these runners demonstrated superior ability in limiting decrements in running speed during the later stages. Likewise, Lambert et $\mathrm{al}^{16}$ investigated the pacing strategies adopted by 67 runners during a $100 \mathrm{~km}$ ultra-marathon running race and observed a tendency for the better (fastest ten out of 67) performing runners to adopt a relatively even pacing strategy during the first $50 \mathrm{~km}$ of a $100 \mathrm{~km}$ race. These runners also experienced the lowest reduction in running velocity during the second $50 \mathrm{~km}$. It is possible that these runners have, to the best of their ability, attempted to adopt an even pacing strategy, but involuntarily slowed down due to significant metabolic $\mathrm{c}^{4,5,9,23,68} \mathrm{and} /$ or psychological disturbances..$^{5,25,37,47}$ It is important to note that, although an even pacing strategy may theoretically be optimal for performance during endurance exercise due to the balance of propulsive and resistive forces, this strategy may not be physiologically optimal. Indeed, large variations in power output to counteract external perturbations such as topography and wind (discussed in "Environmental factors" below) are required to maintain an even pacing strategy. Such changes in power output have been shown to increase physiological strain and reduce performance. ${ }^{69}$ Under such circumstances, variations in speed to maintain a relatively even distribution of power output/energetic resources may likely be a more optimal strategy for athletes.

\section{Race dynamics and drafting in mass-start events}

Numerous factors associated with race dynamics may also influence optimal and self-selected pacing in triathlon. The ability to conserve and maximize efficiency of one's energy is crucial for triathlon success. During mass-start events such 
as triathlon, athletes are often able to draft within a sheltered position behind another competitor, ${ }^{70}$ which provides for an opportunity to conserve energy, and plays a considerable role in determining both optimal and self-selected pacing during triathlon. ${ }^{47}$ For example, drafting during the swim portion of a triathlon allows an athlete to achieve a faster swim time by drafting off a faster swimmer, which conserves energy for the latter cycle and run disciplines. ${ }^{70}$ Certainly, drafting has been shown to improve swimming economy by reducing the drag force on the drafter $(10 \%-26 \%),{ }^{71-73}$ blood lactate concentration (31\%), rating of perceived exertion $(21 \%),{ }^{74}$ and oxygen consumption $(5 \%-10 \%){ }^{41,73-79}$ The relatively fast speeds often observed at the beginning of triathlon events (especially for wave-starts or group starts) are therefore likely to be influenced by race dynamics. Indeed, starting at a swimming velocity faster than their mean speeds will allow athletes to achieve a strategic position behind the fastest swimmer so as to conserve energy throughout the remainder of the swim, reduce the delaying effects of previous waves of swimmers, and allow them to be better positioned for the beginning of the cycle discipline. ${ }^{32-34}$ For instance, during a seven-lap $40.2 \mathrm{~km}$ cycle draft-legal World Cup triathlon, Vleck et $\mathrm{a}^{133}$ observed that male swim finishers who were not able to maintain a position within the lead swim group (within 13.6 \pm 8.5 seconds of the lead swimmer's finishing time) were unsuccessful in staying within the first two cycle packs by the end of lap one. Subsequently, these athletes had to cycle faster in laps two and three in order to "bridge the gap" by the end of lap three.

Similarly, drafting is extremely important to performance within the cycle discipline of triathlon. Drafting during cycling drastically reduces fluid resistance (ie, aerodynamic drag $)^{36,70,80,81}$ and, thus, can conserve a considerable amount of energy. For example, in a simulated sprint distance triathlon, Hausswirth et $\mathrm{al}^{80}$ observed a reduction in oxygen uptake $(-14 \%)$, heart rate $(-7.5 \%)$, and pulmonary ventilation $(-30.8 \%)$ when athletes were drafting $0.2-0.5 \mathrm{~m}$ behind a lead cyclist at an mean speed of $39.5 \mathrm{~km} \cdot \mathrm{h}^{-1}$, compared with the non-drafting situation. Furthermore, the number of athletes present in the drafting pack may also influence the speed and energy utilization, which has a significant influence on the subsequent run. ${ }^{80}$ As such, the size and configuration of cycling packs, as well as the tactical locations of athletes within a pack, may considerably influence the distribution of exercise intensity within draft-legal races. Rather than maintaining an even pacing, drafting in the cycle discipline likely induces a stochastic power profile due to acute tactical changes in pacing. ${ }^{3,36}$ Indeed, Le Meur et al ${ }^{132}$ observed that, during a six-lap $40 \mathrm{~km}$ cycle discipline of an elite Olympic-distance triathlon, male athletes adopted an initial positive pacing strategy during the first three laps, followed by a slight increase in speed during lap four, which was maintained until the end of the cycle discipline. In a separate $40 \mathrm{~km}$ elite Olympic-distance cycle discipline, Vleck et $\mathrm{a}^{33}$ observed an entirely different pacing strategy, where male athletes began by increasing their speed for up to $50 \%$ of the distance $(20.1 \mathrm{~km})$, followed by decrements in speed until the $33.5 \mathrm{~km}$ point, and then increasing their speed thereafter until the finish. Collectively, these studies indicate that pacing during triathlons could be highly variable and out of the individual's control depending on drafting and race dynamics; the beneficial effects of drafting may limit an athlete to cycling in a pack, which is highly influenced by peer race tactics. ${ }^{82,83}$

Due to the importance of maintaining a position with the lead athletes during the cycle discipline, the pacing of top contenders during elite competitions is highly dependent on the pacing strategy of the leading athlete, who may attempt to maximize their lead, which may or may not be matched by other competitors. Therefore, pacing could be highly variable across the three disciplines. For instance, three studies ${ }^{32-34}$ that have examined the pacing of elite athletes in draft-legal races have collectively reported that these athletes typically adopt a positive pace during the swim, a variable pace during the cycle (characterized by fluctuations in speed), and a reverse J-shaped pace (explained below) during the run (Figure 1). A tactic commonly observed during elite races is the contribution of minimal effort during cycling in order to maximize run performance, which could partly explain the highly variable cycling pace. ${ }^{32-34}$ Race dynamics may be further influenced by the strengths of the individual, who may adopt different pacing strategies in order to maximize performance of a specific discipline. However, the influences of specific tactics and pacing strategies adopted by individual athletes on other competitors and race dynamics in triathlons are yet to be examined. Although elite athletes are permitted to draft during the cycle discipline during selected races, age-group triathletes are not. ${ }^{10,11,32-34}$ For instance, in non-draft-legal

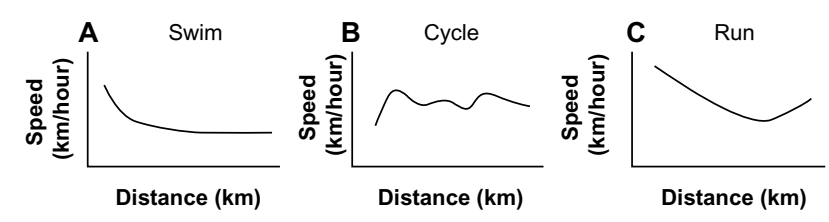

Figure I Example of pacing adopted by elite athletes during a draft-legal Olympicdistance triathlon.

Notes: (A) Swim. (B) Cycle. (C) Run. 
events, athletes are required to maintain a specified distance behind the next competitor, and are given a specified time to pass the front athlete when overtaking. Specifically, a cycling distance of 7-12 m (draft zone) is maintained in the Ironman, and a passing time of 20-25 seconds is enforced once entering the draft zone. The overtaken athlete then has the same specified time to drop back out of the draft zone. This difference in drafting ruling could significantly affect pacing during triathlon, as cycling during non-draft-legal events is more similar to that of an individual time trial, as reflected by the stability of power output during flat cycling in a triathlon race. ${ }^{35,84}$ Under such conditions, race dynamics are likely to have less of an influence on cycling performance and, thus, athletes are likely to have a greater reliance on intrinsic control over pacing. However, it is also important to note that, despite the lack of drafting during the cycle discipline of some triathlon events, the race dynamics associated with mass-start events is still likely to influence pacing. Indeed, non-drafting athletes are still required to be positioned near the leading riders to be in contention for a high finish place. Furthermore, regardless of drafting format, all athletes are permitted to draft during the swim and run disciplines of all triathlon events. Collectively, the actions and tactics of competitors are likely to dramatically influence pacing during triathlon competition.

\section{Environmental factors}

While race dynamics are likely to increase the variability of exercise intensity within both draft-legal and non-draft-legal races, pacing could also be influenced by other external factors such as water currents, wind conditions, ${ }^{35,39,85}$ topography, ${ }^{10,42,85}$ environmental heat, and humidity. ${ }^{86}$ For example, a higher mean power output of $192 \pm 21 \mathrm{~W}$ was reported during women's world cup flat cycling races, as compared with $169 \pm 17 \mathrm{~W}$ observed during hilly races. ${ }^{87}$ Conversely, power output during the Tour de France increased with increasing hill gradient. Specifically, mean power outputs during flat, semi-mountainous, and mountainous stages were $218 \pm 21$ $\mathrm{W}, 228 \pm 22 \mathrm{~W}$, and $234 \pm 13 \mathrm{~W}$, respectively. ${ }^{88}$ It is important to note that, when examining the pacing of athletes, the relationship between power output and speed is non-linear and could be vastly different; therefore, power output and speed should not be used interchangeably, especially when external factors such as fluid resistance ${ }^{39}$ and gravity ${ }^{42}$ vary. Indeed, in an attempt to maintain an even pace, a variable power output is sometimes necessary to account for periods of high external resistance such as traveling uphill ${ }^{42,89}$ or into a headwind. ${ }^{39,89}$ For instance, Atkinson and Brunskill ${ }^{39}$ and
Atkinson et $\mathrm{al}^{89}$ demonstrated in laboratory conditions that, when compared with a freely-paced trial, superior cycling performance was achieved when athletes increased power output uphill or into a headwind and decreased power output when external resistance was low (ie, downhill and with a tailwind). However, no previous studies have examined the extent to which athletes adopt a varied distribution of power output in order to account for varying external conditions in actual triathlon competitions. Interestingly, a relatively even power output has been observed in well-trained triathletes during the cycle discipline of the Ironman ${ }^{35}$ and half-Ironman events ( $\mathrm{Wu}$, unpublished data, 2014; Figure 2) despite fluctuating wind conditions. In this case, it is possible that maintaining physiological homeostasis, minimizing neuromuscular fatigue, and conserving metabolic reserves for the run may be more important during ultra-distance triathlons than the time saved from varying power output to counteract the debilitating effects of wind on performance. Furthermore, the swim, cycle, and run disciplines of triathlons are performed at different velocities and with dissimilar external resistances. Such differences in the resistance to locomotion will influence the degree of variation in energy expenditure necessary to adopt optimal pacing strategies.

During triathlon racing, pacing may be further influenced by heat and humidity. ${ }^{90,91}$ For instance, Peiffer and Abbiss ${ }^{86}$ observed an earlier decline in power output and subsequently lower mean power output during a $40 \mathrm{~km}$ time trial at $32^{\circ} \mathrm{C}$, as compared with $17^{\circ} \mathrm{C}, 22^{\circ} \mathrm{C}$, and $27^{\circ} \mathrm{C}$. Despite the difference in performance, pacing strategies observed were remarkably similar, characterized by a gradual reduction in power followed by an increase toward the final stages of cycling. ${ }^{86}$ However, optimal pacing during triathlon in the heat will also depend on the abovementioned factors such as wind, topography, physiological characteristics, fitness, and rate of athlete's heat dissipation. Further modeling research into the relationships between ambient temperature, power output, energy expenditure, drafting, and external resistance is required to predict the optimal pacing strategies during different triathlon distances.

\section{Transition}

One of the challenges in triathlon is in successfully maneuvering the swim-to-cycle transition (T1) and cycle-to-run transition (T2). Indeed, the presence of a preceding swim before the cycle and the cycle before the run can negatively impact physiological stress and performance. For instance, Kreider et $\mathrm{al}^{92}$ observed a $16.8 \%$ reduction in power output during 75 minutes of cycling after $800 \mathrm{~m}$ of swimming, 


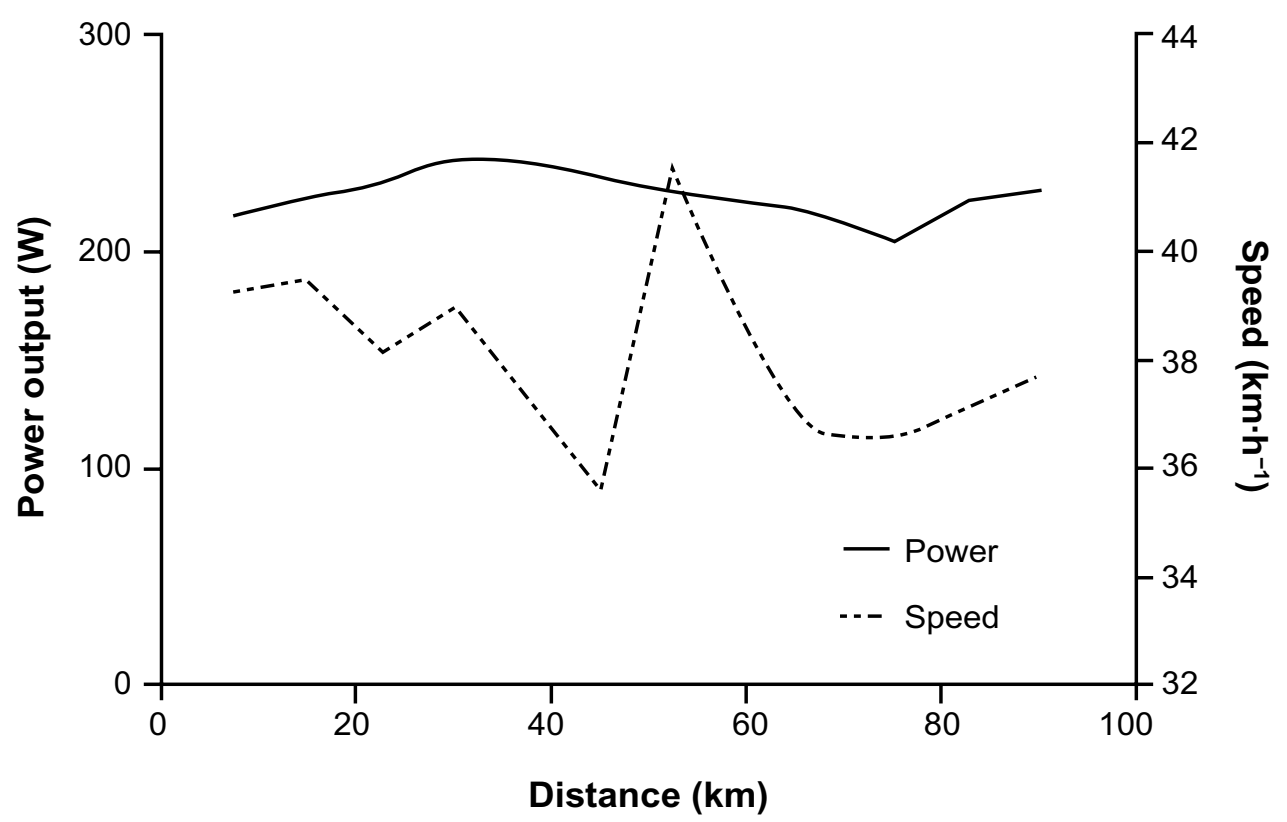

Figure 2 Power output and speed of a well-trained triathlete during the cycle discipline of a half-Ironman event. Note: Fluctuations in speed compared to a relatively even power profile are of note.

compared with a control 75-minute cycle without prior swimming. Similarly, Guezennec et al ${ }^{51}$ observed a significant increase in oxygen cost $\left(51.2\right.$ versus $\left.47.8 \mathrm{~mL} \cdot \mathrm{kg}^{-1} \cdot \mathrm{min}^{-1}\right)$ and heart rate (162 versus $156 \mathrm{bpm}$ ) during the $10 \mathrm{~km}$ run of an Olympic-distance triathlon following cycling, as compared with a control run without prior cycling. Certainly, differences in muscle groups utilized, ${ }^{3}$ energy expenditure, and requirements between $\mathrm{T} 1^{31,51,92}$ and $\mathrm{T} 2^{93}$ may contribute to the complexity of pacing within triathlon. The sections below aim to illustrate the influence of $\mathrm{T} 1$ and $\mathrm{T} 2$ transitions on triathlon pacing in further detail.

\section{Swim to cycle}

T1 consists of changing from a sport that is upper-body dominant to one that is predominantly lower-body dominant, which may be difficult due to blood pooling in the upper extremities after swimming. ${ }^{3}$ The detrimental effect of a prior swimming bout on subsequent cycling performance has been well documented..$^{31,51,76,92,94,95}$ Indeed, when preceded with a 1,500 m swim (equal distance with an Olympic triathlon swim), an increase in energy cost (13\% lower gross efficiency, $56 \%$ higher blood lactate concentrations, 9\% higher heart rate, $5 \%$ higher $\mathrm{VO}_{2}$ ) was observed during the first 5 minutes of a 30-minute cycle at $75 \%$ maximal aerobic power. ${ }^{76}$ Nevertheless, the swim discipline within triathlon events is likely performed at a relatively high intensity, due to the importance of exiting the water in the lead group to form part of the first pack of cyclists, especially during draft-legal races. ${ }^{34,94,96}$
However, there is research to suggest that decreasing swim intensity would decrease subsequent fatigue and improve overall triathlon performance. ${ }^{31}$ Indeed, Peeling et al ${ }^{31}$ investigated the effect of swimming at $80 \%-85 \%, 90 \%-95 \%$, and $98 \%-102 \%$ of the mean speed achieved during a control swim trial on subsequent cycle and run performance. They reported a faster cycling time when the swim was performed at $80 \%-85 \%$ and $90 \%-95 \%$, as compared with $98 \%-102 \%{ }^{31}$ Further, a faster overall triathlon time was observed when swimming at $80 \%-85 \%$, as compared with $98 \%-102 \%$. This indicates that the pacing adopted during the swim of a triathlon not only affects subsequent cycling performance, but may also have an influence on overall triathlon performance. As adopting a low swimming speed may be counter-productive to overall triathlon performance, especially during drafting events, improving swimming ability may be crucial for athletes to achieve a high swim finishing position without exceeding $90 \%$ of their maximal swim speed. ${ }^{31}$

\section{Cycle to run}

The negative effects of a preceding cycle bout on running performance is well known (for a review see Millet and Vleck ${ }^{97}$ ). These effects have been attributed to an increase in oxygen cost, ${ }^{50-52,92}$ glycogen depletion, ${ }^{50-52}$ ventilatory muscle fatigue, ${ }^{50}$ dehydration, ${ }^{51,52,98}$ decreased pulmonary compliance, exercise induced hypoxemia, ${ }^{99}$ muscle fatigue, ${ }^{52,100}$ and redistribution of muscle blood flow. Novice athletes reportedly experienced loss of coordination, ${ }^{97}$ associated 
with changes in gait frequency $(1.5-2.0$ to $1-1.5 \mathrm{~Hz}$ in cycling and running, respectively) and/or transition from a predominantly non-weight-bearing activity (cycling) to one bearing two to three times of body mass (running), ${ }^{52,101}$ and a shift from primarily concentric to stretch-shortening-type eccentric contractions in running. ${ }^{102}$ Therefore, it appears that careful pacing manipulation during the cycle discipline could benefit subsequent run performance. Indeed, it has been suggested that athletes may be able to alter power output and cadence during cycling in order to maximize subsequent running performance. ${ }^{79,84,103,104}$ For instance, Bernard et $\mathrm{al}^{84}$ investigated the effect of pacing during a $20 \mathrm{~km}$ time-trial on subsequent $5 \mathrm{~km}$ running performance within the laboratory setting. The authors reported a significantly faster running performance $(1,118 \pm 72$ seconds) after a constant intensity cycle bout as compared with variable $(1,168 \pm 73$ seconds) and freely chosen intensity cycle bouts $(1,134 \pm 64$ seconds), suggesting that an even cycling pacing strategy is preferable during a sprint distance triathlon. In accordance with these findings, an increase in power output during the final stages of a $20 \mathrm{~km}$ cycling bout has been shown to be detrimental to $5 \mathrm{~km}$ running performance. ${ }^{84}$ As such, during a World Cup Olympic triathlon, Le Meur et al ${ }^{32}$ observed a significant decrease in power output in both elite males $(17 \%, P<0.05)$ and females $(19 \%, P<0.05)$ from the first (lap one) to the last lap (lap six); presumably this was an attempt to minimize fatigue and maximize subsequent running performance. Taken together, these studies suggest that, depending on the drafting nature and distance of the race, different combinations of pacing for specific disciplines of the triathlon are required for optimal performance.

It is plausible that the drafting nature of the race could affect pacing during triathlon transitions. During draft-legal races, an increase in speed is sometimes observed during $\mathrm{T} 1{ }^{34}$ and $\mathrm{T} 2,{ }^{34,97}$ likely in an attempt to achieve a prime position for the subsequent discipline. Indeed, there is evidence to suggest a positive relationship between $\mathrm{T} 2$ and overall finishing position..$^{97}$ However, there remains a paucity of research data that clarifies the effect of $\mathrm{T} 1$ and $\mathrm{T} 2$ on pacing during triathlon. There is, however, an abundance of research on the increase in speed during the final stages of a triathlon run. This sprint finish is widely referred to as an "end-spurt." $\$, 25,30,105$ The end-spurt phenomenon is characterized by an increase in speed after $80 \%-90 \%$ completion of the race when the athletes are supposedly most fatigued, and may be greater during draft-legal races where race outcomes are more likely decided by a sprint finish. The end-spurt has been associated with an increased central drive, provided that there is sufficient metabolic reserve ${ }^{25}$ and that the end-spurt poses no catastrophic risk to physiological homeostasis. ${ }^{8,105}$ Yet, the maintenance of an overly large reserve capacity toward the end of the event could be evocative of a suboptimal pacing strategy, where a higher running velocity could have been maintained for a longer duration of the run discipline. ${ }^{15,38,45,85}$ Therefore, the ability to manipulate run pacing such that energy stores are optimally utilized could highly influence triathlon performance. There is evidence to suggest that the run in a non-draft-legal triathlon is performed without an end-spurt. Taylor et al ${ }^{106}$ compared the pacing strategy adopted during a sprint triathlon run, as compared with a control $5 \mathrm{~km}$ run, and found no differences in run pacing. Further, no increase in running speed was observed in the final kilometer. It is, however, important to note that laboratory simulated triathlons are usually performed as isolated trials and may not replicate the psychosocial factors and peer influence experienced during actual races. Further research is required to elucidate pacing strategies adopted during non-drafting triathlons.

\section{Biological sex}

The influence of internal and external factors on pacing may differ between males and females, due to internal (physiological and morphological ${ }^{107}$ ) and external (participation rates ${ }^{108}$ ) differences between sexes (for review see Lepers et al ${ }^{107}$ ). The physiological differences have been attributed to a $12 \%-15 \%$ lower maximal oxygen consumption $\left(\mathrm{VO}_{2 \max }\right),{ }^{109} 5 \%-10 \%$ lower hemoglobin concentration, and $\sim 8 \%$ higher body fat percentage in elite females, as compared with elite males. ${ }^{107,110,111}$ Le Meur et al ${ }^{32}$ observed that, during a World Cup Olympic-distance triathlon, females spent a greater percentage of total time (45\%) above maximal aerobic power when cycling up hills, as compared with males $(32 \%)$. Females also tended not to bridge gaps that were formed during the cycle section. ${ }^{33}$ These results are in accordance with those previously reported in events based on a single mode of locomotion, such as a cross-country mountain bike World Championships. ${ }^{82}$ It is speculated that the lower maximal aerobic power-to-weight ratio in females results in greater time spent on uphill sections of the race. ${ }^{32}$ Since it has been previously shown that better cycling performance results from minimizing time spent traveling uphill ${ }^{89}$ and adopting a more even distribution of speed, it appears that females could benefit from improving uphill riding performance or maximal aerobic power/weight ratio. ${ }^{32,82}$ Collectively, research on the pacing differences in cycling/ triathlon between sexes suggests that external factors such 
as topography and wind are likely to be more detrimental to performance in females than in males. ${ }^{32,33,45,82,112}$ As such, it is possible that drafting may benefit females more than males in triathlon and cycling performance. This could alter the pacing strategies that are adopted based on the drafting nature of the race. Indeed, there is evidence to suggest that males typically begin the swim ${ }^{33}$ and cycle disciplines ${ }^{32}$ of draft-legal Olympic races with a relatively more "aggressive" initial starting pace, as compared with females. However, despite the aforementioned physiological and morphological differences between sexes, and the weight bearing nature of running, ${ }^{45,107}$ male and female triathletes typically adopt similar positive pacing during draft-legal Olympic-distance triathlon runs. ${ }^{11,32}$ To date, the benefit of this positive pacing strategy remains unclear. ${ }^{11,32}$

It is possible that different pacing strategies could be observed with males and females during non-drafting triathlons, due to the various extents of influence of race dynamics ${ }^{107}$ and peer influence (participation rates and depth of field ${ }^{108}$ between sexes. For example, the sex differences in participation are generally higher in nondrafting triathlons compared with draft-legal elite races. This difference has been shown to account for more than one-third of the differences in sex variations in marathon running. ${ }^{113}$ Therefore, further research is warranted to elucidate the specific differences in influence of physiological, sociological, and possibly psychological factors on pacing between sexes.

\section{Age}

The decline in endurance performance due to advancing age is well-known. ${ }^{102,107,110,114,115}$ The sex gap for the age-related declines in endurance performance remains at 10\%-15\% until 50 years of age, and progressively widens thereafter. ${ }^{107,110}$ The gap between sexes for overall triathlon performance ranges from $12 \%$ to $18.2 \%,{ }^{107}$ however, there is a similar widening between sexes after 55 years in the Olympic and Ironman triathlons. ${ }^{110,116}$ Further, the duration of triathlon also influences the age-related declines in triathlon performance. Specifically, more pronounced declines have been observed during shorter-distance triathlons, as compared with the Ironman. ${ }^{107}$ The age-related decline in triathlon performance has been attributed to: a reduction in $\mathrm{VO}_{2 \max } ;{ }^{107,114}$ a reduction in muscle strength and mass; attenuation of repair and hypertrophy of skeletal muscles; ${ }^{117}$ lower resting muscle glycogen content; ${ }^{13}$ and a reduction in training volume and intensity. ${ }^{107}$ As these factors play a critical role in fatigue development, aging can influence the distribution of self-selected pace by triathletes of different age-groups. However, there is no research to date on the influence of age on pacing in triathlon. Nevertheless, previous research has demonstrated the effect of age on pacing during prolonged endurance exercise. ${ }^{118}$ Specifically, March et $\mathrm{al}^{118}$ investigated the age-related changes in pacing of 319 finishers during a marathon, and reported that women and older athletes adopted a relatively more-even pacing as compared with men and younger athletes. Certainly, the complexity of triathlon and the increase in oxygen cost during running in a triathlon ${ }^{51}$ indicates that pacing during triathlon could alter with age.

\section{Influence of performance throughout individual disciplines on subsequent triathlon performance}

Due to the importance of discipline-specific and overall pacing in triathlon, it is important to note the relationships between each individual discipline and overall performance during pacing. Indeed, the performance during each discipline can influence overall triathlon performance to different extents. ${ }^{12,31-34,51,52}$ Therefore, the interdisciplinary associations are highlighted below. Performance during the swim discipline of a triathlon is likely to be of greater importance within shorter distance triathlons (sprint and Olympic), as compared with longer distance triathlons (halfIronman and Ironman). Indeed, evidence indicates that the position achieved during the first $200-500 \mathrm{~m}$ in a $1,500 \mathrm{~m}$ Olympic-distance triathlon swim largely determines the final swim outcome. ${ }^{32-35}$ Supporting this, a significant correlation ( $r=0.99$ and 0.97 for males and females, respectively) was observed between the position attained at $350 \mathrm{~m}$ into a swim of 1,500 $\mathrm{m}$ and final swim outcome during a World Cup Olympic-distance competition. ${ }^{32}$ In a separate World Cup race, the final swim position and velocity was reported to correlate with overall race position ( $r=0.44$ and -0.52 , respectively) ${ }^{34}$ Furthermore, there is evidence to suggest that decreasing swim intensity could benefit subsequent cycling and, therefore, overall sprint-triathlon performance. ${ }^{31}$ This indicates that the pacing strategy adopted during the swim of a triathlon not only affects subsequent cycling performance, but may also have a global influence on overall triathlon performance.

During longer half-Ironman and Ironman distances, however, the percentage contribution of swimming to total race time is considerably lower $(\sim 10 \%$ and $\sim 20 \%$ during longer and shorter distances, respectively). ${ }^{4}$ Hence, it has been suggested that performance in the swim portion in longer triathlon events is not tantamount to overall performance. ${ }^{119}$ 
Since the majority of field studies have been based on the Olympic distance, further studies on the pacing strategies adopted during the swim on subsequent triathlon performance in other distances, in both draft-legal and non-draft-legal races, are warranted.

In draft-legal racing, athletes commonly complete the cycling discipline in packs (pelotons). The effect of pacing and performance during cycling appears to affect overall performance more than swimming due to the high correlation of overall winners belonging to the first-finishing cycling pack. Indeed, a higher correlation was observed between cycle and overall performance $(r=0.52-0.74)$ as compared with swimming and overall performance $(r=0.36-0.52)^{32-34}$ during draft-legal Olympic-distance triathlons. Presently, there is a lack of research on the effect of pacing during swim and cycle bouts on subsequent running performance. ${ }^{51,106}$ Further research is warranted to determine the pacing strategies required for optimal pacing in disciplines prior to the run in a triathlon.

The run discipline of a triathlon is completed last, following considerable energy expenditure in the swim and cycle disciplines. Additionally, the full weight-bearing nature of running ${ }^{89,95}$ is likely to induce more muscular fatigue and damage when compared with swimming and cycling. Certainly, a decrease in running efficiency after a previous cycling bout ${ }^{51,52}$ suggests higher metabolic costs, which are likely to induce fatigue and affect performance. This is especially critical in triathlons where energy efficiency could play a significant role in determining performance. ${ }^{120}$ Thus, it seems reasonable to postulate that performance during the run discipline would have the greatest influence on overall race position. Indeed, the highest correlations have been reported between running performance and final race position $(r=0.71-0.99)$ as compared with other disciplines during the Olympic-distance triathlon. ${ }^{32-34}$ However, further research is needed to determine the relationships between the three individual disciplines and overall standings during other triathlon distances such as the sprint, half-Ironman, and Ironman.

A reverse $\mathrm{J}$-shaped pacing strategy is commonly observed during the elite $10 \mathrm{~km}$ Olympic-distance triathlon run. ${ }^{11,32-34}$ The reverse $\mathrm{J}$-shaped pacing is characterized by a fast start followed by a reduction in speed and a subsequent increase in speed toward the end of the run (for review see Abbiss and Laursen ${ }^{5}$ ). It is currently unclear whether a reverse $\mathrm{J}$-shaped pacing is optimal for the triathlon run. However, due to the importance of run performance relative to overall performance, it is highly likely that optimizing run pacing could benefit triathlon performance. To date, only a single study has investigated the effect of manipulating run pace on overall triathlon performance. Hausswirth et a ${ }^{12}$ investigated the effect of altering the first run kilometer (by 5\% slower, $10 \%$ slower, and 5\% faster than the mean speed during a control run) during a simulated Olympicdistance triathlon in ten highly trained male triathletes. They reported significantly faster $10 \mathrm{~km}$ performance in the $-5 \%$ condition, as compared with the $+5 \%$ and $-10 \%$ condition A slower run performance observed in the $+5 \%$ trial was attributed to the downregulation of exercise intensity in a feedforward manner controlled by the brain, to prevent catastrophic failure of the physiological systems. ${ }^{12}$ Further, a faster start requires higher metabolic demands, ${ }^{6,20,121,122}$ which could result in premature fatigue prior to the end of the race, as demonstrated by the $+5 \%$ run. As such, a slightly slower to even start, which resultantly elicits a more even overall run pace, may be ideal for an Olympicdistance triathlon run. However, further research is required to determine the optimal run pacing strategies during other triathlon distances.

Although there is an extensive amount of triathlon research, no studies have systematically investigated the effect of distance, age, and sex on triathlon pacing. Further modeling research is required to establish the relationships between pacing during individual disciplines and overall performance across different triathlon distances.

\section{Conclusion}

The understanding of pacing in multisport events such as the triathlon is still poorly understood. The manipulation of pacing in triathlon is complex, due to the sequential swim, cycle, and run disciplines, and is attributed to the fatigue that accumulates between disciplines. Furthermore, triathlon pacing can be influenced by a multitude of intrinsic and extrinsic factors including wind velocity, topography, influence of other competitors, transition, age, drafting, biological sex, and duration of event. It appears that a reduced intensity in prior swimming and cycling could result in faster subsequent cycling and running performance, respectively. However, the optimal pacing strategies across the sprint, Olympic, half-Ironman, and Ironman triathlons are currently unclear. Further research is required to establish the best possible pacing strategies to adopt across various triathlon distances.

\section{Disclosure}

The authors declare no conflicts of interest in this work. 


\section{References}

1. Lepers R, Rüst CA, Stapley PJ, Knechtle B. Relative improvements in endurance performance with age: evidence from 25 years of Hawaii Ironman racing. Age (Dordr). 2013;35(3):953-962.

2. Rüst CA, Knechtle B, Knechtle P, et al. Gender difference and agerelated changes in performance at the long-distance duathlon. J Strength Cond Res. 2013;27(2):293-301

3. Bentley DJ, Millet GP, Vleck VE, McNaughton LR. Specific Aspects of Contemporary Triathlon: Implications for Physiological Analysis and Performance. Sports Med. 2002;32(6):345-359.

4. Laursen PB, Rhodes EC. Factors affecting performance in an ultraendurance triathlon. Sports Med. 2001;31(3):195-209.

5. Abbiss CR, Laursen PB. Describing and understanding pacing strategies during athletic competition. Sports Med. 2008;38(3):239-252.

6. Foster C, Snyder AC, Thompson NN, Green MA, Foley M, Schrager M. Effect of pacing strategy on cycle time trial performance. Med Sci Sports Exerc. 1993;25(3):383-388.

7. Foster C, deKoning JJ, Hettinga F, et al. Effect of competitive distance on energy expenditure during simulated competition. Int J Sports Med. 2004;25(3):198-204.

8. Noakes TD. Time to move beyond a brainless exercise physiology: the evidence for complex regulation of human exercise performance. $\mathrm{Appl}$ Physiol Nutr Metab. 2011;36(1):23-35.

9. Abbiss CR, Laursen PB. Models to explain fatigue during prolonged endurance cycling. Sports Med. 2005;35(10):865-898.

10. Bernard T, Hausswirth C, Le Meur Y, Bignet F, Dorel S, Brisswalter J. Distribution of power output during the cycling stage of a Triathlon World Cup. Med Sci Sports Exerc. 2009;41(6):1296-1302.

11. Le Meur Y, Bernard T, Dorel S, et al. Relationships between triathlon performance and pacing strategy during the run in an international competition. Int J Sports Physiol Perform. 2011;6(2):183-194.

12. Hausswirth C, Le Meur Y, Bieuzen F, Brisswalter J, Bernard T. Pacing strategy during the initial phase of the run in triathlon: influence on overall performance. Eur J Appl Physiol. 2010;108(6):1115-1123.

13. Lepers R, Sultana F, Bernard T, Hausswirth C, Brisswalter J. Age-related changes in triathlon performances. Int J Sports Med. 2010;31(4): 251-256.

14. Edwards AM, Polman RC. Pacing and awareness: brain regulation of physical activity. Sports Med. 2013;43(11):1057-1064.

15. Tucker R, Lambert MI, Noakes TD. An analysis of pacing strategies during men's world-record performances in track athletics. Int J Sports Physiol Perform. 2006;1(3):233-245.

16. Lambert MI, Dugas JP, Kirkman MC, Mokone GG, Waldeck MR. Changes in running speeds in a $100 \mathrm{~km}$ ultra-marathon race. J Sports Sci Med. 2004;3(3):167-173.

17. Micklewright D, Papadopoulou E, Swart J, Noakes T. Previous experience influences pacing during $20 \mathrm{~km}$ time trial cycling. Br J Sports Med. 2010;44(13):952-960.

18. Aisbett B, Lerossignol P, McConell GK, Abbiss CR, Snow R. Influence of all-out and fast start on 5-min cycling time trial performance. Med Sci Sports Exerc. 2009;41(10):1965-1971.

19. Albertus Y, Tucker R, St Clair Gibson A, Lambert EV, Hampson DB, Noakes TD. Effect of distance feedback on pacing strategy and perceived exertion during cycling. Med Sci Sports Exerc. 2005;37(3): 461-468.

20. Thompson KG, MacLaren DP, Lees A, Atkinson G. The effect of even, positive and negative pacing on metabolic, kinematic and temporal variables during breaststroke swimming. Eur J Appl Physiol. 2003;88(4-5): $438-443$.

21. Skorski S, Faude O, Caviezel S, Meyer T. Reproducibility of Competition Pacing Profiles in Elite Swimmers. Int J Sports Phys Perf. 2014;9(2):217-225.

22. Garland SW. An analysis of the pacing strategy adopted by elite competitors in 2000 m rowing. Br J Sports Med. 2005;39(1):39-42.

23. Rauch HG, St Clair Gibson A, Lambert EV, Noakes TD. A signalling role for muscle glycogen in the regulation of pace during prolonged exercise. Br J Sports Med. 2005;39(1):34-38.
24. Nybo L, Secher NH. Cerebral perturbations provoked by prolonged exercise. Prog Neurobiol. 2004;72(4):223-261.

25. Gibson A, Lambert EV, Rauch LHG, et al. The role of information processing between the brain and peripheral physiological systems in pacing and perception of effort. Sports Med. 2006;36(8):705-722.

26. Williams CA, Bailey SD, Mauger AR. External exercise information provides no immediate additional performance benefit to untrained individuals in time trial cycling. Br J Sports Med. 2012;46(1): 49-53.

27. Nikolopoulos V, Arkinstall MJ, Hawley JA. Pacing strategy in simulated cycle time-trials is based on perceived rather than actual distance. $J$ Sci Med Sport. 2001;4(2):212-219.

28. Marcora SM, Staiano W, Manning V. Mental fatigue impairs physical performance in humans. J Appl Physiol (1985). 2009;106(3):857-864

29. Parry D, Chinnasamy C, Papadopoulou E, Noakes T, Micklewright D. Cognition and performance: anxiety, mood and perceived exertion among Ironman triathletes. Br J Sports Med. 2011;45(14):1088-1094.

30. Renfree A, West J, Corbett M, Rhoden C, St Clair Gibson A. Complex interplay between determinants of pacing and performance during $20 \mathrm{~km}$ cycle time trials. Int J Sports Physiol Perform. 2012;7(2):121-129.

31. Peeling PD, Bishop DJ, Landers GJ. Effect of swimming intensity on subsequent cycling and overall triathlon performance. Br J Sports Med. 2005;39(12):960-964.

32. Le Meur Y, Hausswirth C, Dorel S, Bignet F, Brisswalter J, Bernard T. Influence of gender on pacing adopted by elite triathletes during a competition. Eur J Appl Physiol. 2009;106(4):535-545.

33. Vleck VE, Bentley DJ, Millet GP, Burgi A. Pacing during an elite Olympic distance triathlon: comparison between male and female competitors. J Sci Med Sport. 2008;11(4):424-432.

34. Vleck VE, Bürgi A, Bentley DJ. The consequences of swim, cycle, and run performance on overall result in elite olympic distance triathlon. Int J Sports Med. 2006;27(1):43-48.

35. Abbiss CR, Quod MJ, Martin DT, et al. Dynamic pacing strategies during the cycle phase of an Ironman triathlon. Med Sci Sports Exerc. 2006;38(4):726-734.

36. Hausswirth C, Brisswalter J. Strategies for Improving Performance in Long Duration Events: Olympic Distance Triathlon. Sports Med. 2008;38(11):881-891

37. Baron B, Moullan F, Deruelle F, Noakes TD. The role of emotions on pacing strategies and performance in middle and long duration sport events. Br J Sports Med. 2009;45(6):511-517.

38. Tucker R. The anticipatory regulation of performance: the physiological basis for pacing strategies and the development of a perception-based model for exercise performance. Br J Sports Med. 2009;43(6):392-400.

39. Atkinson G, Brunskill A. Pacing strategies during a cycling time trial with simulated headwinds and tailwinds. Ergonomics. 2000;43(10): $1449-1460$

40. de Koning JJ, Bobbert MF, Foster C. Determination of optimal pacing strategy in track cycling with an energy flow model. J Sci Med Sport. 1999;2(3):266-277.

41. Swain DP. A model for optimizing cycling performance by varying power on hills and in wind. Med Sci Sports Exerc. 1997;29(8): 1104-1108.

42. Atkinson G, Peacock O, Law M. Acceptability of power variation during a simulated hilly time trial. Int J Sports Med. 2007;28(2):157-163.

43. Etter F, Knechtle B, Bukowski A, Rüst CA, Rosemann T, Lepers R. Age and gender interactions in short distance triathlon performance. J Sports Sci. 2013;31(9):996-1006.

44. Hamilton MT, Gonzalez-Alonso J, Montain SJ, Coyle EF. Fluid replacement and glucose infusion during exercise prevent cardiovascular drift. J Appl Physiol (1985). 1991;71(3):871-877.

45. Lambert EV, St Clair Gibson A, Noakes TD. Complex systems model of fatigue: integrative homoeostatic control of peripheral physiological systems during exercise in humans. Br J Sports Med. 2005;39(1):52-62.

46. Zaryski C, Smith DJ. Training principles and issues for ultra-endurance athletes. Curr Sports Med Rep. 2005;4(3):165-170. 
47. Tucker R, Noakes TD. The physiological regulation of pacing strategy during exercise: a critical review. Br J Sports Med. 2009;43(6):e1.

48. Hermansen L. Effect of Metabolic Changes on Force Generation in Skeletal Muscle During Maximal Exercise. Proceedings of the Ciba Foundation Symposium 82 - Human Muscle Fatigue: Physiological Mechanisms, 1981. Chichester, UK: Porter R, Whelan J, editors; John Wiley \& Sons, Ltd.; 2008.

49. Fabiato A, Fabiato F. Effects of $\mathrm{pH}$ on the myofilaments and the sarcoplasmic reticulum of skinned cells from cardiace and skeletal muscles. J Physiol. 1978;276:233-255.

50. Hue O, Le Gallais D, Chollet D, Boussana A, Préfaut C. The influence of prior cycling on biomechanical and cardiorespiratory response profiles during running in triathletes. Eur J Appl Physiol Occup Physiol. 1998;77(1-2):98-105.

51. Guezennec CY, Vallier JM, Bigard AX, Durey A. Increase in energy-cost of running at the end of a triathlon. Eur J Appl Physiol Occup Physiol. 1996;73:440-445.

52. Hausswirth C, Bigard AX, Berthelot M, Thomaïdis M, Guezennec CY Variability in energy cost of running at the end of a triathlon and a marathon. Int J Sports Med. 1996;17(8):572-579.

53. Bergström J, Hermansen L, Hultman E, Saltin B. Diet, muscle glycogen and physical performance. Acta Physiol Scand. 1967;71(2):140-150.

54. Dennis SC, Noakes TD, Hawley JA. Nutritional strategies to minimize fatigue during prolonged exercise: fluid, electrolyte and energy replacement. J Sports Sci. 1997;15(3):305-313.

55. Johnson NA, Stannard SR, Chapman PG, Thompson MW. Effect of altered pre-exercise carbohydrate availability on selection and perception of effort during prolonged cycling. Eur J Appl Physiol. 2006;98(1) $62-70$.

56. Millet GY, Lepers R, Maffiuletti NA, Babault N, Martin V, Lattier G. Alterations of neuromuscular function after an ultramarathon. $J$ Appl Physiol (1985). 2002;92(2):486-492.

57. Millet GY, Lepers R. Alterations of neuromuscular function after prolonged running, cycling and skiing exercises. Sports Med. 2004;34(2): 105-116.

58. Gibson A, Schabort EJ, Noakes TD. Reduced neuromuscular activity and force generation during prolonged cycling. Am J Physiol Regul Integr Comp Physiol. 2001;281(1):R187-R196.

59. Bailey SJ, Vanhatalo A, DiMenna FJ, Wilkerson DP, Jones AM. Fast-start strategy improves VO2 kinetics and high-intensity exercise performance. Med Sci Sports Exerc. 2011;43(3):457-467.

60. Bishop D, Bonetti D, Dawson B. The influence of pacing strategy on VO2 and supramaximal kayak performance. Med Sci Sports Exerc. 2002;34(6):1041-1047.

61. Burnley M, Jones AM. Oxygen uptake kinetics as a determinant of sports performance. Eur J Sport Sci. 2007;7(2):63-79.

62. Thompson KG, MacLaren DP, Lees A, Atkinson G. The effects of changing pace on metabolism and stroke characteristics during highspeed breaststroke swimming. J Sports Sci. 2004;22(2):149-157.

63. Cherry PW, Lakomy HK, Nevill ME, Fletcher RJ. Constant external work cycle exercise-the performance and metabolic effects of allout and even-paced strategies. Eur J Appl Physiol Occup Physiol. 1997;75(1):22-27.

64. Paterson S, Marino FE. Effect of deception of distance on prolonged cycling performance. Percept Mot Skills. 2004;98(3 Pt 1): 1017-1026.

65. Fukuba Y, Whipp BJ. A metabolic limit on the ability to make up for lost time in endurance events. J Appl Physiol (1985). 1999;87(2): 853-861.

66. Zamparo P, Bonifazi M, Faina M, et al. Energy cost of swimming of elite long-distance swimmers. Eur J Appl Physiol. 2005;94(5-6):697-704.

67. Skorski S, Faude O, Abbiss CR, Caviezel S, Wengert N, Meyer T. Influence of Pacing Manipulation on Performance of Juniors in Simulated $400 \mathrm{~m}$ Swim Competition. Int J Sports Physiol Perform. Epub January 15, 2014.

68. Neumayr G, Pfister R, Mitterbauer G, et al. Exercise intensity of cycletouring events. Int J Sports Med. 2002;23(7):505-509.
69. Thomas K, Stone M, St Clair Gibson A, Thompson K, Ansley L. The effect of an even-pacing strategy on exercise tolerance in well-trained cyclists. Eur J Appl Physiol. 2013;113(12):3001-3010.

70. Brisswalter J, Hausswirth C. Consequences of drafting on human locomotion: benefits on sports performance. Int J Sports Physiol Perform. 2008;3(1):3-15.

71. Chatard JC, Chollet D, Millet G. Performance and drag during drafting swimming in highly trained triathletes. Med Sci Sports Exerc. 1998;30(8):1276-1280.

72. Millet G, Chollet D, Chatard JC. Effects of drafting behind a two- or a six-beat kick swimmer in elite female triathletes. Eur J Appl Physiol. 2000;82(5-6):465-471.

73. Chollet D, Hue O, Auclair F, Millet G, Chatard JC. The effects of drafting on stroking variations during swimming in elite male triathletes. Eur J Appl Physiol. 2000;82(5-6):413-417.

74. Bassett DR Jr, Flohr J, Duey WJ, Howley ET, Pein RL. Metabolic responses to drafting during front crawl swimming. Med Sci Sports Exerc. 1991;23(6):744-747.

75. Neumayr G, Pfister R, Mitterbauer G, Maurer A, Hoertnagl H. Effect of ultramarathon cycling on the heart rate in elite cyclists. Br J Sports Med. 2004;38(1):55-59.

76. Delextrat A, Brisswalter J, Hausswirth C, Bernard T, Vallier JM. Does prior $1500-\mathrm{m}$ swimming affect cycling energy expenditure in welltrained triathletes? Can J Appl Physiol. 2005;30(4):392-403.

77. Padilla S, Mujika I, Angulo F, Goiriena JJ. Scientific approach to the 1-h cycling world record: a case study. J Appl Physiol (1985). 2000;89(4): $1522-1527$.

78. Schumacher YO, Ahlgrim C, Prettin S, Pottgiesser T. Physiology, power output, and racing strategy of a race across America finisher. Med Sci Sports Exerc. 2011;43(5):885-889.

79. Suriano R, Vercruyssen F, Bishop D, Brisswalter J. Variable power output during cycling improves subsequent treadmill run time to exhaustion. J Sci Med Sport. 2007;10(4):244-251.

80. Hausswirth C, Lehénaff D, Dréano P, Savonen K. Effects of cycling alone or in a sheltered position on subsequent running performance during a triathlon. Med Sci Sports Exerc. 1999;31(4):599-604.

81. Hausswirth C, Vallier JM, Lehenaff D, et al. Effect of two drafting modalities in cycling on running performance. Med Sci Sports Exerc. 2001;33(3):485-492.

82. Abbiss CR, Ross ML, Garvican LA, et al. The distribution of pace adopted by cyclists during a cross-country mountain bike World Championships. J Sports Sci. 2013;31(7):787-794.

83. Abbiss CR, Straker L, Quod MJ, Martin DT, Laursen PB. Examining pacing profiles in elite female road cyclists using exposure variation analysis. Br J Sports Med. 2010;44(6):437-442.

84. Bernard T, Vercruyssen F, Mazure C, Gorce P, Hausswirth C, Brisswalter J. Constant versus variable-intensity during cycling: effects on subsequent running performance. Eur J Appl Physiol. 2007;99(2): $103-111$.

85. Gibson A, Noakes TD. Evidence for complex system integration and dynamic neural regulation of skeletal muscle recruitment during exercise in humans. Br J Sports Med. 2004;38(6):797-806.

86. Peiffer JJ, Abbiss CR. Influence of environmental temperature on $40 \mathrm{~km}$ cycling time-trial performance. Int J Sports Physiol Perform. 2011;6(2):208-220.

87. Ebert TR, Martin DT, McDonald W, Victor J, Plummer J, Withers RT. Power output during women's World Cup road cycle racing. Eur J Appl Physiol. 2005;95(5-6):529-536.

88. Vogt S, Schumacher YO, Roecker K, et al. Power output during the Tour de France. Int J Sports Med. 2007;28(9):756-761.

89. Atkinson G, Peacock O, Passfield L. Variable versus constant power strategies during cycling time-trials: prediction of time savings using an up-to-date mathematical model. J Sports Sci. 2007;25(9): 1001-1009.

90. Tucker R, Rauch L, Harley YX, Noakes TD. Impaired exercise performance in the heat is associated with an anticipatory reduction in skeletal muscle recruitment. Pflug Arch. 2004;448(4):422-430. 
91. Tucker R, Marle T, Lambert EV, Noakes TD. The rate of heat storage mediates an anticipatory reduction in exercise intensity during cycling at a fixed rating of perceived exertion. J Physiol. 2006;574(Pt 3): 905-915.

92. Kreider RB, Boone T, Thompson WR, Burkes S, Cortes CW. Cardiovascular and thermal responses of triathlon performance. Med Sci Sports Exerc. 1988;20(4):385-390.

93. Bijker KE, de Groot G, Hollander AP. Differences in leg muscle activity during running and cycling in humans. Eur J Appl Physiol. 2002;87(6):556-561.

94. Peeling P, Landers G. Swimming intensity during triathlon: a review of current research and strategies to enhance race performance. J Sports Sci. 2009;27(10):1079-1085.

95. Delextrat A, Bernard T, Vercruyssen F, Hausswirth C, Brisswalter J. Influence of swimming characterisics on performance during a swimto-cycle transition. Sci Sports. 2003;18:188-195.

96. Pacheco AG, dos Santos Leite G, De Lucas RD, Guglielmo LG. The influence of swimming performance in triathlon: implications for training and competition. Brazilian Journal of Kinanthropometry and Human Performance. 2012;14(2):232-241.

97. Millet GP, Vleck VE. Physiological and biomechanical adaptations to the cycle to run transition in Olympic triathlon: review and practical recommendations for training. Br J Sports Med. 2000;34(5):384-390.

98. Hausswirth C, Bigard AX, Guezennec CY. Relationships between running mechanics and energy cost of running at the end of a triathlon and a marathon. Int J Sports Med. 1997;18(5):330-339.

99. Caillaud C, Serre-Cousiné O, Anselme F, Capdevilla X, Préfaut C. Computerized tomography and pulmonary diffusing capacity in highly trained athletes after performing a triathlon. J Appl Physiol (1985). 1995;79(4):1226-1232.

100. Marino GW, Geogan J. Work-energy analysis of triathletes running under bike/run and run only conditions. Paper presented at: International Symposium on Biomechanics in Sports; June 23; 1993; Amherst, MA, USA.

101. Quigley EJ, Richards JG. Original Research The effects of cycling on running mechanics. J Appl Biomech. 1996;12(4):470-479.

102. Bernard T, Sultana F, Lepers R, Hausswirth C, Brisswalter J. Agerelated decline in olympic triathlon performance: effect of locomotion mode. Exp Aging Res. 2010;36(1):64-78.

103. Vercruyssen F, Suriano R, Bishop D, Hausswirth C, Brisswalter J. Cadence selection affects metabolic responses during cycling and subsequent running time to fatigue. Br J Sports Med. 2005;39(5): 267-272.

104. Vercruyssen F, Brisswalter J, Hausswirth C, Bernard T, Bernard O, Vallier JM. Influence of cycling cadence on subsequent running performance in triathletes. Med Sci Sports Exerc. 2002;34(3):530-536.

105. Roelands B, de Koning J, Foster C, Hettinga F, Meeusen R. Neurophysiological determinants of theoretical concepts and mechanisms involved in pacing. Sports Med. 2013;43(5):301-311.
106. Taylor D, Smith MF, Vleck VE. Effects of residual fatigue on pace regulation during sprint-distance triathlon running. Epub February 7-9, 2013.

107. Lepers R, Knechtle B, Stapley PJ. Trends in triathlon performance: Effects of sex and age. Sports Med. 2013;43(9):851-863.

108. Deaner RO. Physiology Does Not Explain All Sex Differences in Running Performance. Med Sci Sports Exerc. 2013;45(1):146-147.

109. Sparling PB. A meta-analysis of studies comparing maximal oxygen uptake in men and women. Res Q Exerc Sport. 1980;51(3):542-552.

110. Lepers R, Maffiuletti NA. Age and gender interactions in ultraendurance performance: insight from the triathlon. Med Sci Sports Exerc. 2011;43(1):134-139.

111. Joyner MJ. Physiological limiting factors and distance running: influence of gender and age on record performances. Exerc Sport Sci Rev. 1993;21:103-133.

112. van Ingen Schenau GJ, de Koning JJ, de Groot G. Optimisation of sprinting performance in running, cycling and speed skating. Sports Med. 1994;17(4):259-275.

113. Hunter SK, Stevens AA. Sex differences in marathon running with advanced age: physiology or participation? Med Sci Sports Exerc. 2013;45(1):148-156.

114. Tanaka H, Seals DR. Invited review: Dynamic exercise performance in Masters athletes: insight into the effects of primary human aging on physiological functional capacity. J Appl Physiol (1985). 2003;95(5):2152-2162.

115. Reaburn P, Dascombe B. Endurance performance in masters athletes. Eur Rev Aging Phys Act. 2008;5(1):31-42.

116. Ransdell LB, Vener J, Huberty J. Masters athletes: an analysis of running, swimming and cycling performance by age and gender. J Exerc Sci Fit. 2009;7(2):S61-S73.

117. Verdijk LB, Koopman R, Schaart G, Meijer K, Savelberg HH, van Loon LJ. Satellite cell content is specifically reduced in type II skeletal muscle fibers in the elderly. Am J Physiol Endocrinol Metab. 2007;292(1):E151-E157.

118. March DS, Vanderburgh PM, Titlebaum PJ, Hoops ML. Age, sex, and finish time as determinants of pacing in the marathon. J Strength Cond Res. 2011;25(2):386-391.

119. Laursen PB, Rhodes EC, Langill RH. The effects of 3000-m swimming on subsequent 3 -h cycling performance: implications for ultraendurance triathletes. Eur J Appl Physiol. 2000;83(1):28-33.

120. Hausswirth $C$, Lehénaff $D$. Physiological demands of running during long distance runs and triathlons. Sports Med. 2001;31:679-689.

121. Billat VL, Slawinski J, Danel M, Koralsztein JP. Effect of free versus constant pace on performance and oxygen kinetics in running. Med Sci Sports Exerc. 2001;33(12):2082-2088.

122. Hettinga FJ, De Koning JJ, Broersen FT, Van Geffen P, Foster C. Pacing strategy and the occurrence of fatigue in 4000-m cycling time trials. Med Sci Sports Exerc. 2006;38(8):1484-1491.
Open Access Journal of Sports Medicine

\section{Publish your work in this journal}

Open Access Journal of Sports Medicine is an international, peer-reviewed, open access journal publishing original research, reports, reviews and commentaries on all areas of sports medicine. The manuscript management system is completely online and includes a very quick and fair peer-review system.

\section{Dovepress}

Visit http://www.dovepress.com/testimonials.php to read real quotes from published authors. 